\title{
Business Cycles with Spirit of Capitalism and Conspicuous Consumption in a Multi-Country Growth Model
}

\author{
Wei-Bin Zhang ${ }^{1}$ \\ ${ }^{1}$ Professor, Ritsumeikan Asia Pacific University, Japan \\ Correspondence: Wei-BinZhang, Professor, Ritsumeikan Asia Pacific University, Japan.
}

Received: April 10, 2017

Accepted: June 22, $2017 \quad$ Online Published: July 11, 2017

doi:10.5539/ibr.v10n8p58

URL: https://doi.org/10.5539/ibr.v10n8p58

\begin{abstract}
This paper generalizes the global economic growth model with spirit of capitalism, social status, and conspicuous consumption recently proposed by Zhang (2016). Zhang's model examines the role of spirit of capitalism, social status, and conspicuous consumption in national and international economic development, trade patterns, and distribution of income and wealth between countries. The multi-country growth model treats social status and wealth accumulation as endogenous variables. This paper generalizes the model by Zhang through making all exogenous constant parameters as exogenous time-dependent parameters. We demonstrate how the system reacts to exogenous periodic perturbations.
\end{abstract}

Keywords: spirit of capitalism, oscillations; global economic growth, social status, inequality in income and wealth, conspicuous consumption

\section{Introduction}

The purpose of this study is to generalizes the global economic growth model with spirit of capitalism, social status, and conspicuous consumption recently proposed by Zhang (2016). We generalize Zhang's model by making all exogenous constant parameters as exogenous time-dependent parameters. With the generalized model we can show how the system reacts to any type of exogenous changes. This study emphasizes periodic perturbations in order to illustrate sources of business cycles.

The role of conspicuous consumption on economic behavior has been vividly described by Veblen (1899) in The Theory of the Leisure Class. In his theory conspicuous consumption is considered as symbols of social status. Duesenberry (1949) holds that social status may be enhanced through following the consumption standard of the social classes above them. Rege (2008) points out that social status may serve a signal of non-observable abilities. Rege (2008: 240) states that "By investing in social status a person can thus improve his chance of engaging in a complementary interaction with a high ability person. The idea that status can serve as a signal of abilities is not new and has been captured in several models. It has, for example, been demonstrated that workers can signal their ability to employers by undertaking some seemingly irrelevant but costly activity interpreted as status consumption (Frank, 1985a) or social culture (Fang, 2001) and that people can "burn money" on fashions to signal abilities in a "dating game" (Pesendorfer)." Some economists include social status in growth models (see, for instance, Cole et al., 1992; Konrad, 1992; Fershtman et al., 1996; Rauscher, 1997; Chang, et al. 2004; Clemens, 2004; Fisher and Hof, 2005; Chen and Guo, 2009, 2011). Nevertheless, there are only a few models which include endogenous social status in formal international growth theory. The model by Zhang (2016) is the first formal model which introduces social status into the neoclassical global growth model with national inequalities in income and wealth. The model is an international growth model with wealth accumulation and changes in social status in a multi-country economy. The economic system is built on the basis of the Solow model, the Uzawa two-sector model, and the Oniki-Uzawa trade model.

This paper studies business cycles. Business oscillations and business cycles are exogenous or endogenous. Economics also suggests different sources of business cycles. For instance, the real business-cycle theory considers business cycles as the efficient response to various exogenous shifts in the real economic variables. In the literature of economic theory, there are only a few formal models which can properly deal with exogenous cycles in the real business-cycle theory on the basis of microeconomics. This study introduces exogenous real shocks to the neoclassical global growth model to demonstrate the existence of business cycles due to real shocks. It should be noted that modern nonlinear dynamic economic theory studies business cycles in dynamic systems with or without 
any exogenous influences. Many theoretical and empirical research about mechanisms and phenomena of economic fluctuations are published (e.g., Zhang, 1991, 2005, 2006; Lorenz, 1993; Flaschel et al 1997; Chiarella and Flaschel, 2000; Shone, 2002; Gandolfo, 2005; Puu, 2011; Tian, 2015). These studies deal with economic business cycles on the basis of different economic theories. This study introduces real shocks to Zhang's model. The main difference between this study and Zhang (2016) is that this study deals with the exogenously fixed parameters as exogenous time-dependent parameters. Section 2 generalizes Zhang's model. In Section 3 we demonstrate that the movement of the global economy of $J$ countries are described by $J$ differential equations. The simulation shows some dynamic properties of the global economy of three national economies. Section 4 carries out comparative dynamic analysis with regard to exogenous periodic oscillations. Section 5 concludes the study.

\section{The Multi-Country Trade Growth Model with Social Status}

This section is to generalize Zhang's global growth model with spirit of capitalism and conspicuous consumption by making all exogenous constant parameters to be exogenous time-dependent (Zhang, 2016). The generalization allows us to analyze time-dependent shocks. The world economy consists any number of national economies, each country being indexed by $j=1, \ldots, J$. Country $j$ 's fixed population is denoted by $N_{j},(j=1, \ldots, J)$. Like Uzawa's two-sector growth model (Uzawa, 1961), each country has two - capital good and one consumer good sectors. We describe the production sectors on the basis of neoclassical growth theory (e.g., Burmeister and Dobell, 1970; Azariadis, 1993; Barro and Sala-i-Martin, 1995). The modelling of international trade follows the Oniki-Uzawa trade model. As in Ikeda and Ono (1992), we assume that all the countries produce homogenous capital good. The consumer good sector produces goods and services and consumer goods are not tradable in the international markets. Households hold assets of the economy. Households distribute their incomes to consume and save. Exchanges are conducted in perfectly competitive markets. Only households undertake saving. All earnings of firms are distributed in the form of payments to factors of production. We measure prices in terms of the capital good, with the price of the capital good being unit. We denote wage and interest rates by $w_{j}(t)$ and $r_{j}(t)$, respectively, in the $j$ th country. Free trade implies that the interest rate is equal throughout the world economy, i.e., $r(t)=r_{j}(t)$. Capital is depreciated at an exponential rate $\delta_{k j}(t)$. We use $p_{j}(t)$ to represent the price of consumer good in country $j$. We use subscript index, $i$ and $s$ to stand for capital good sector and consumer good sector, respectively. Let $N_{j m}(t)$ and $K_{j m}(t)$ represent for the labor force and capital stocks employed by country $j$ 's sector $m$. We use $F_{j m}(t)$ to stand for the output level of sector $m$ in country $j$.

\subsection{The Capital Good Sectors}

The production functions of the capital good sectors are specified as follows

$$
F_{j i}(t)=A_{j i}(t) K_{j i}^{\alpha_{j i}(t)}(t) N_{j i}^{\beta_{i i}(t)}(t), A_{j i}(t), \alpha_{j i}(t), \beta_{j i}(t)>0, \alpha_{j i}(t)+\beta_{j i}(t)=1,
$$

where $A_{j i}(t), \alpha_{j i}(t)$, and $\beta_{j i}(t)$ are time-dependent positive parameters. The marginal conditions of the capital goods sectors are given by

$$
r(t)+\delta_{k j}(t)=\frac{\alpha_{j i}(t) F_{j i}(t)}{K_{j i}(t)}, w_{j}(t)=\frac{\beta_{j i}(t) F_{j i}(t)}{N_{j i}(t)} .
$$

\subsection{The Consumer Good Sectors}

We specify the production functions of the consumer good sectors as follows

$$
F_{j s}(t)=A_{j s}(t) K_{j s}^{\alpha_{j s}(t)}(t) N_{j s}^{\beta_{j s}(t)}(t), \alpha_{j s}(t)+\beta_{j s}(t)=1, \alpha_{j s}(t), \beta_{j s}(t)>0,
$$

where $A_{j s}(t), \alpha_{j s}(t)$, and $\beta_{j s}(t)$ are time-dependent technological parameters of the consumer good sector. We have the following marginal conditions

$$
r(t)+\delta_{j k}=\frac{\alpha_{j s} p_{j}(t) F_{j s}(t)}{K_{j s}(t)}, w_{j}(t)=\frac{\beta_{j s} p_{j}(t) F_{j s}(t)}{N_{j s}(t)} .
$$

\subsection{Current Income and Disposable Income}

Let $\bar{K}_{j}(t)$ represent the total wealth owned by country $j$. We use $\bar{k}_{j}(t)$ to stand for per capita wealth of country $j$, where $\bar{k}_{j}(t)=\bar{K}_{j}(t) / N_{j}(t)$, Per capita current income from the interest payment $r(t) \bar{k}_{j}(t)$, and the wage payment $w_{j}(t)$, is 


$$
y_{j}(t)=r(t) \bar{k}_{j}(t)+w_{j}(t) .
$$

The per capita disposable income in each national economy is the sum of the current disposable income and the value of wealth. We have

$$
\hat{y}_{j}(t)=y_{j}(t)+\bar{k}_{j}(t)
$$

\subsection{Description of Social Status}

To illustrate Zhang's approach, we illustrate a few approaches to social status in formal growth theory. By considering social status as a function of wealth, Chen and Guo (2009) assume that each household maximizes its lifetime utility $U$ as follows

$$
U=\int_{0}^{\infty}\left[\frac{c^{1-\sigma}(t)-1}{1-\sigma}+\beta \frac{k^{1-\sigma}(t)-1}{1-\sigma}\right] e^{\rho t} d t,
$$

where $\beta$ measures the degree of the spirit of capitalism, $c(t)$ and $k(t)$, stand for the consumption level and capital stock, respectively, and $\rho$ implies the time discount rate. We also apply the idea that social status is measured with the level of capital ownership. Chen and Guo (2011) use the following utility function

$$
U=\int_{0}^{\infty} \frac{\left[c(t)(k(t) / K(t))^{\beta}\right]^{1-\sigma}-1}{1-\sigma} e^{-\rho t} d t .
$$

The household gets utility from the wealth-based social status. The status is measured by the physical-capital ownership $k(t)$ relative to the economy-wide level of physical capital stock $K(t)$. They use $\beta>0$ to measure the degree of the spirit of capitalism. Corneo and Jeanne (1999) apply the utility function as follows

$$
U=\int_{0}^{\infty}[u(c(t))+v(t)] e^{\rho t} d t
$$

where $v(t)$ is an individual's social esteem. As in Zhang (2016), we specify social status function $j$ as a function of wealth as follows

$$
\omega_{j}\left(\left(\bar{k}_{j}(t)\right), t\right)=\omega_{j 0}(t)+\omega_{j L}(t) \bar{k}_{j}(t)
$$

where $\omega_{j 0}(t)$ and $\omega_{j L}(t)$ positive parameters. In (6) we see a positive relationship between status and the household's wealth.

\subsection{Budget and Utility Function}

Let $s_{j}(t)$ and $c_{j}(t)$ stand for the representative household's savings and consumer good. The budget constraint is

$$
p_{j}(t) c_{j}(t)+s_{j}(t)=\hat{y}_{j}(t)
$$

The utility level $U_{j}(t)$ is dependent on $c_{j}(t)$ and $s_{j}(t)$ as follows

$$
U_{j}(t)=c_{j}^{\xi_{j 0}\left(\omega_{j}(t), t\right)}(t) s_{j}^{\lambda_{j 0}\left(\omega_{j}(t), t\right)}(t), \quad \xi_{j 0}\left(\omega_{j}(t), t\right), \lambda_{j 0}\left(\omega_{j}(t), t\right)>0,
$$

where $\xi_{j 0}\left(\omega_{j}(t), t\right)$ is the propensity to consume consumer goods and $\lambda_{j 0}\left(\omega_{j}(t), t\right)$ the propensity to save.

\subsection{Social Status and Propensities to Save and to Consume}

Social status affects the propensities to consume and to save as follows

$$
\xi_{j 0}\left(\omega_{j}(t), t\right)=\bar{\xi}_{j 0}(t)+\tilde{\xi}_{j 0}(t) \omega_{j}(t), \quad \lambda_{j 0}\left(\omega_{j}(t), t\right)=\bar{\lambda}_{j 0}(t)+\tilde{\lambda}_{j 0}(t) \omega_{j}(t),
$$

where $\bar{\xi}_{j 0}(t)$ and $\bar{\lambda}_{j 0}(t)$ are time-dependent positive parameters, and $\tilde{\xi}_{j 0}(t)$ and $\tilde{\lambda}_{j 0}(t)$ are time-dependent parameters which may be either positive, zero, or negative. The propensity to consume is increased by social status through conspicuous consumption. The propensity to save is affected by social status as social status is enhanced with rises in wealth. The spirit of capitalism may influence the propensity to save. 


\subsection{Optimal Household Behavior}

Maximizing the utility subject to (8) yields

$$
p(t) c_{j}(t)=\xi_{j}\left(\left(\bar{k}_{j}(t)\right), t\right) \hat{y}_{j}(t), s_{j}(t)=\lambda_{j}\left(\left(\bar{k}_{j}(t)\right), t\right) \hat{y}_{j}(t),
$$

where

$$
\begin{aligned}
& \xi_{j}\left(\left(\bar{k}_{j}(t)\right), t\right) \equiv \rho_{j}\left(\left(\bar{k}_{j}(t)\right), t\right) \xi_{j 0}\left(\left(\bar{k}_{j}(t)\right), t\right), \lambda_{j}\left(\left(\bar{k}_{j}(t)\right), t\right) \equiv \rho_{j}\left(\left(\bar{k}_{j}(t)\right), t\right) \lambda_{j 0}\left(\left(\bar{k}_{j}(t)\right), t\right), \\
& \rho_{j}\left(\left(\bar{k}_{j}(t)\right), t\right) \equiv \frac{1}{\xi_{j 0}\left(\left(\bar{k}_{j}(t)\right), t\right)+\lambda_{j 0}\left(\left(\bar{k}_{j}(t)\right), t\right)} .
\end{aligned}
$$

\subsection{Wealth Accumulation}

According to the definition of $s_{j}(t)$, we have the following equation to describe the change in the household's wealth

$$
k_{j}^{\&}(t)=s_{j}(t)-\bar{k}_{j}(t)
$$

The equation states that the change in wealth is savings minus dissaving.

\subsection{Demand and Supply}

Let $K(t)$ stand for the world's capital stocks. The total capital stock employed by country $j, K_{j}(t)$, is fully employed

$$
K_{j i}(t)+K_{j s}(t)=K_{j}(t), \quad N_{j i}(t)+N_{j s}(t)=N_{j}(t) .
$$

\subsection{Equilibrium in Global Capital Markets}

The world's total capital stock equals the world's wealth

$$
K(t)=\sum_{j=1}^{J} K_{j}(t)=\sum_{j=1}^{J} \bar{K}_{j}(t)=\sum_{j=1}^{J} \bar{k}_{j}(t) N_{j},
$$

where $\bar{K}_{j}(t)$ is the wealth owned by country $j$.

2.11 Demand and Supply

Equilibrium for consumer goods implies

$$
c_{j}(t) N_{j}(t)=F_{j s}(t), \quad j=1, \ldots, J .
$$

\subsection{Trade Balances}

The world's output level of capital good is the world net savings

$$
S(t)-K(t)+\sum_{j=1}^{J} \delta_{j k}(t) K_{j}(t)=F(t),
$$

where

$$
S(t) \equiv \sum_{j=1}^{J} s_{j}(t) N_{j}, \quad F(t) \equiv \sum_{j=1}^{J} F_{j}(t) .
$$

We completed the model. The model is structurally general. In formal economic growth literature some well-known models can be treated as its special cases. For instance, if we assume all the parameters to be constant over time, our model is the same as Zhang's model (Zhang, 2016). Our model is structurally similar to neoclassical growth theory (Solow, 1956; Uzawa, 1961) when the world economy is composed identical economies. It is structurally similar to the Oniki-Uzawa model (Oniki and Uzawa, 1965).

\section{The World Economic Dynamics}

The world economy consists of any (finite) number of national economies. Although the dynamic system contains many time-dependent parameters, we succeed in finding a computational procedure for plotting the movement of the world economy at any point in time. We first introduce new variables $z_{j}(t)$ by 


$$
z_{j}(t) \equiv \frac{r(t)+\delta_{j k}}{w_{j}(t)}, \quad j=1, \ldots, J
$$

\section{Lemma}

The dynamics of the world economy with $J$ national economies is governed by the following $J$-dimensional differential equations system with $z_{1}(t),\left\{\bar{k}_{j}(t)\right\}$, and $t$, where $\left\{\bar{k}_{j}(t)\right\} \equiv\left(\bar{k}_{2}(t), \Lambda, \bar{k}_{J}(t)\right)$ as the variables

$$
\begin{gathered}
\&(t)=\Lambda_{1}\left(z_{1}(t),\left\{\bar{k}_{j}(t)\right\}, t\right), \\
z_{j}^{\&}(t)=\Lambda_{j}\left(z_{1}(t),\left\{\bar{k}_{j}(t)\right\}, t\right), j=2, \ldots, J,
\end{gathered}
$$

in which $\Lambda_{j}$ are unique functions of $z_{1}(t),\left\{\bar{k}_{j}(t)\right\}$ and $t$ defined in the Appendix. The other variables are unique functions of $z_{1}(t), \quad\left\{\bar{k}_{j}(t)\right\}$ and $t$ given as follows: $r(t)$ and $w_{j}(t)$ by $(\mathrm{A} 2) \rightarrow z_{j}(t)$ by (A3) $\rightarrow$ $\bar{k}_{1}(t)$ by $(\mathrm{A} 15) \rightarrow \xi_{j}(t)$ by $(\mathrm{A} 13) \rightarrow \lambda_{j}(t)=1-\xi_{j}(t) \rightarrow N_{j s}(t)$ by $(\mathrm{A} 7) \rightarrow N_{j i}(t)$ by $(\mathrm{A} 8) \rightarrow \hat{y}_{j}(t)$ by (A5) $\rightarrow K_{j s}(t)$ and $K_{j i}(t)$ by (A1) $\rightarrow F_{j i}(t)$ and $F_{j s}(t)$ by the definitions $\rightarrow p_{j}(t)$ by (A4) $\rightarrow c_{j}(t)$ and $s_{j}(t)$ by $(13) \rightarrow \bar{K}_{j}^{j}(t)=\bar{k}_{j}(t) N_{j} \rightarrow K_{j}(t)=K_{j i}(t)+K_{j s}(t) \rightarrow K(t)=\sum_{j} \bar{k}_{j}(t) N_{j}$.

By applying the computational procedure in the lemma we can follow the movement of the global economy. We simulate the global economy composed of 3 national economies. The rest of this section follows Zhang (2016) in examining the motion of the system when all the parameters are exogenously fixed. Parameter values specified as follows

$$
\begin{gathered}
\left(\begin{array}{l}
N_{1} \\
N_{2} \\
N_{3}
\end{array}\right)=\left(\begin{array}{l}
10 \\
20 \\
30
\end{array}\right),\left(\begin{array}{l}
A_{1 i} \\
A_{2 i} \\
A_{3 i}
\end{array}\right)=\left(\begin{array}{c}
1.7 \\
1 \\
0.8
\end{array}\right),\left(\begin{array}{l}
A_{1 s} \\
A_{2 s} \\
A_{3 s}
\end{array}\right)=\left(\begin{array}{l}
1.5 \\
0.9 \\
0.7
\end{array}\right),\left(\begin{array}{l}
\alpha_{1 i} \\
\alpha_{2 i} \\
\alpha_{3 i}
\end{array}\right)=\left(\begin{array}{l}
0.31 \\
0.31 \\
0.31
\end{array}\right),\left(\begin{array}{c}
\alpha_{1 s} \\
\alpha_{2 s} \\
\alpha_{3 s}
\end{array}\right)=\left(\begin{array}{c}
0.33 \\
0.33 \\
0.33
\end{array}\right), \\
\left(\begin{array}{c}
\omega_{10} \\
\omega_{20} \\
\omega_{30}
\end{array}\right)=\left(\begin{array}{l}
0.01 \\
0.01 \\
0.01
\end{array}\right),\left(\begin{array}{l}
\omega_{1 \mathrm{~L}} \\
\omega_{2 \mathrm{~L}} \\
\omega_{3 \mathrm{~L}}
\end{array}\right)=\left(\begin{array}{c}
0.01 \\
0.008 \\
0.005
\end{array}\right),\left(\begin{array}{l}
\bar{\lambda}_{10} \\
\bar{\lambda}_{20} \\
\hat{\lambda}_{30}
\end{array}\right)=\left(\begin{array}{c}
0.8 \\
0.75 \\
0.7
\end{array}\right),\left(\begin{array}{l}
\tilde{\lambda}_{10} \\
\tilde{\lambda}_{20} \\
\tilde{\lambda}_{30}
\end{array}\right)=\left(\begin{array}{l}
0.1 \\
0.1 \\
0.1
\end{array}\right),\left(\begin{array}{l}
\bar{\xi}_{10} \\
\bar{\xi}_{20} \\
\bar{\xi}_{30}
\end{array}\right)=\left(\begin{array}{c}
0.12 \\
0.18 \\
0.2
\end{array}\right), \\
\left(\begin{array}{l}
\tilde{\xi}_{10} \\
\tilde{\xi}_{20} \\
\tilde{\xi}_{30}
\end{array}\right)=\left(\begin{array}{l}
0.05 \\
0.05 \\
0.05
\end{array}\right),\left(\begin{array}{l}
\delta_{1 k} \\
\delta_{2 k} \\
\delta_{3 k}
\end{array}\right)=\left(\begin{array}{l}
0.05 \\
0.04 \\
0.04
\end{array}\right) .
\end{gathered}
$$

As in Zhang (2016), the initial conditions are as follows

$$
z_{1}(0)=0.077, \bar{k}_{2}(0)=2.7, \bar{k}_{3}(0)=2 .
$$

The motion of the variables is plotted in Figure 1. In Figure 1, the global income is

$$
Y(t)=Y_{1}(t)+Y_{2}(t)+Y_{3}(t), Y_{j}(t)=F_{j i}(t)+p_{j}(t) F_{j s}(t),
$$



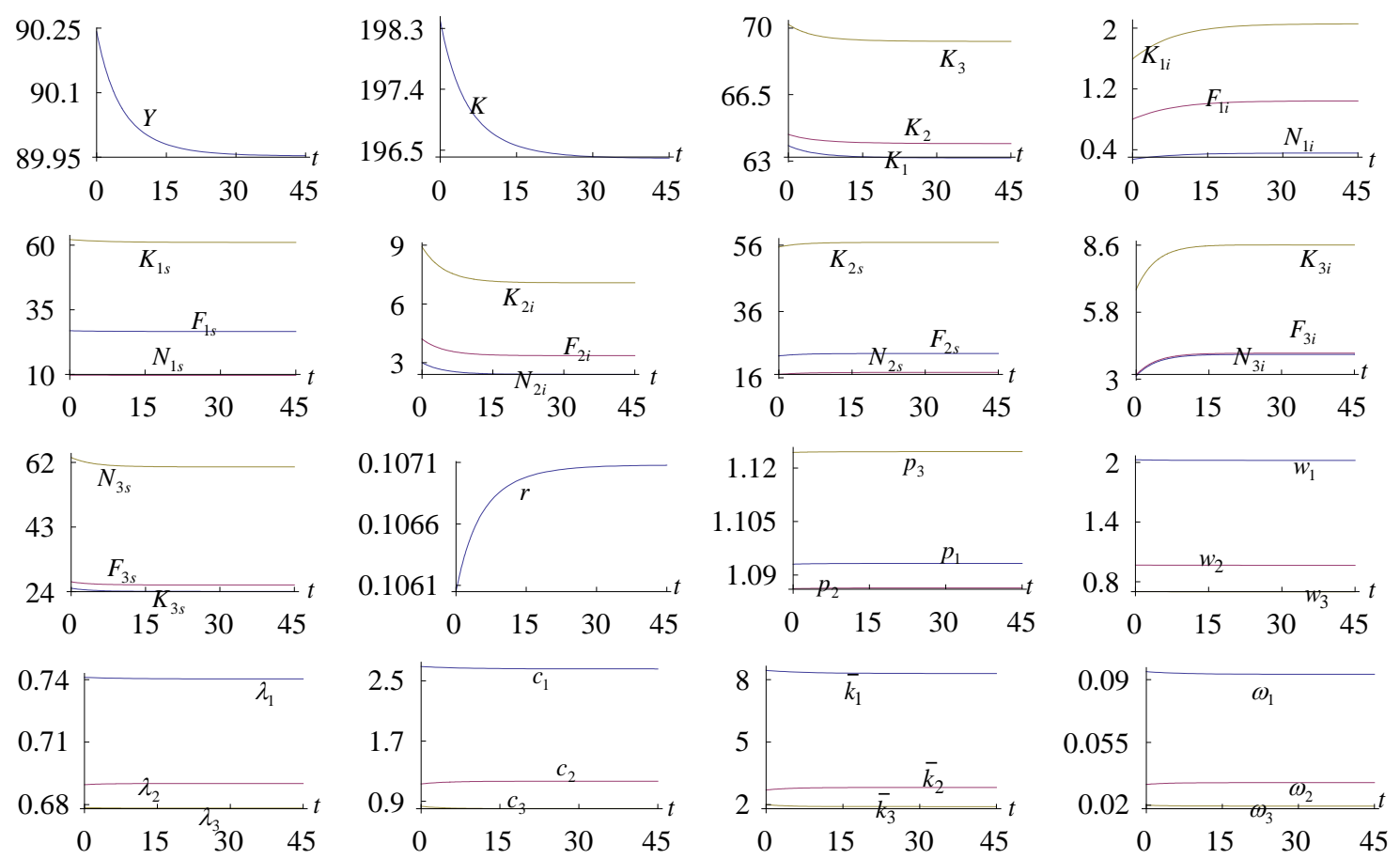

Figure 1. The Motion of the economic system

We identify the following equilibrium point

$$
\begin{gathered}
Y=89.95, K=196.38, r=0.107, \\
\left(\begin{array}{l}
Y_{1} \\
Y_{2} \\
Y_{3}
\end{array}\right)=\left(\begin{array}{l}
30.13 \\
28.69 \\
31.13
\end{array}\right),\left(\begin{array}{l}
\bar{K}_{1} \\
\bar{K}_{2} \\
\bar{K}_{3}
\end{array}\right)=\left(\begin{array}{l}
81.92 \\
56.43 \\
57.03
\end{array}\right),\left(\begin{array}{l}
K_{1} \\
K_{2} \\
K_{3}
\end{array}\right)=\left(\begin{array}{l}
63.16 \\
63.92 \\
69.30
\end{array}\right),\left(\begin{array}{l}
p_{1} \\
p_{2} \\
p_{3}
\end{array}\right)=\left(\begin{array}{l}
1.093 \\
1.086 \\
1.125
\end{array}\right),\left(\begin{array}{l}
w_{1} \\
w_{2} \\
w_{3}
\end{array}\right)=\left(\begin{array}{l}
2.02 \\
0.97 \\
0.70
\end{array}\right), \\
\left(\begin{array}{l}
F_{1 i} \\
F_{2 i} \\
F_{3 i}
\end{array}\right)=\left(\begin{array}{l}
1.04 \\
3.36 \\
4.09
\end{array}\right),\left(\begin{array}{l}
F_{1 s} \\
F_{2 s} \\
F_{3 s}
\end{array}\right)=\left(\begin{array}{c}
26.6 \\
23.32 \\
24.05
\end{array}\right),\left(\begin{array}{l}
N_{1 i} \\
N_{2 i} \\
N_{3 i}
\end{array}\right)=\left(\begin{array}{c}
0.36 \\
2.4 \\
4.04
\end{array}\right),\left(\begin{array}{l}
N_{1 s} \\
N_{2 s} \\
N_{3 s}
\end{array}\right)=\left(\begin{array}{c}
9.64 \\
17.6 \\
25.96
\end{array}\right),\left(\begin{array}{l}
K_{1 i} \\
K_{2 i} \\
K_{3 i}
\end{array}\right)=\left(\begin{array}{l}
2.06 \\
7.08 \\
8.61
\end{array}\right), \\
\left(\begin{array}{l}
K_{1 s} \\
K_{2 s} \\
K_{3 s}
\end{array}\right)=\left(\begin{array}{c}
61.1 \\
56.84 \\
60.69
\end{array}\right),\left(\begin{array}{l}
\omega_{1} \\
\omega_{2} \\
\omega_{3}
\end{array}\right)=\left(\begin{array}{l}
0.09 \\
0.03 \\
0.02
\end{array}\right),\left(\begin{array}{l}
\lambda_{1} \\
\lambda_{2} \\
\lambda_{3}
\end{array}\right)=\left(\begin{array}{l}
0.74 \\
0.69 \\
0.68
\end{array}\right),\left(\begin{array}{l}
\xi_{1} \\
\xi_{2} \\
\xi_{3}
\end{array}\right)=\left(\begin{array}{l}
0.26 \\
0.31 \\
0.32
\end{array}\right),\left(\begin{array}{l}
\bar{k}_{1} \\
\bar{k}_{2} \\
\bar{k}_{3}
\end{array}\right)=\left(\begin{array}{l}
8.29 \\
2.82 \\
1.9
\end{array}\right),\left(\begin{array}{l}
c_{1} \\
c_{2} \\
c_{3}
\end{array}\right)=\left(\begin{array}{c}
2.66 \\
1.17 \\
0.8
\end{array}\right) .
\end{gathered}
$$

We calculate the three eigenvalues as follows

$-0.24,-0.22,-0.13$.

The equilibrium point is stable. The stability guarantees that comparative dynamic analysis can be effectively carried out.

\section{Comparative Dynamic Anal ysis}

As stated in the previous sector, when the parameters are specified as in (17), the economy is characterized of a stable equilibrium point. Zhang (2016) also showed how the economy is affected by once-for-all changes in some parameters. We examine how the economy is affected by time-dependent changes in parameters. We interpret the parameter values in (17) as the long-term average values. We allow small perturbations near these long-term parameter values. First, we introduce a variable $\Delta x(t)$ to stand for the change rate of the variable $x(t)$ due to changes in the parameter value. 


\subsection{Perturbations in the Poor Country's Spirit of Capitalism}

The spirit of capitalism refers to preference for owning more wealth. The measurement of spirit is the weight given to social status in the propensity to save. In our approach countries differ in human capital and spirits of capitalism. We study the effects of the periodic perturbations in the parameter measuring spirit of capitalism as follows

$$
\omega_{3 L}(t)=0.005+0.008 \sin (t) \text {. }
$$

Figure 2 plots the simulation result. As the poor country experiences periodic changes in spirit of capitalism, the social status level of the poor and its propensity to save also experience oscillations. As they are globally connected, the capital good sectors of the global economies experience great changes due to the exogenous perturbations. The wage rates of the three economies experience similar periodic changes. The prices of consumer goods slightly change. With regard to microeconomic variables, the poor country's household experiences periodic changes in the wealth, consumption and preference. The households' behavior of the other two economies change slightly.
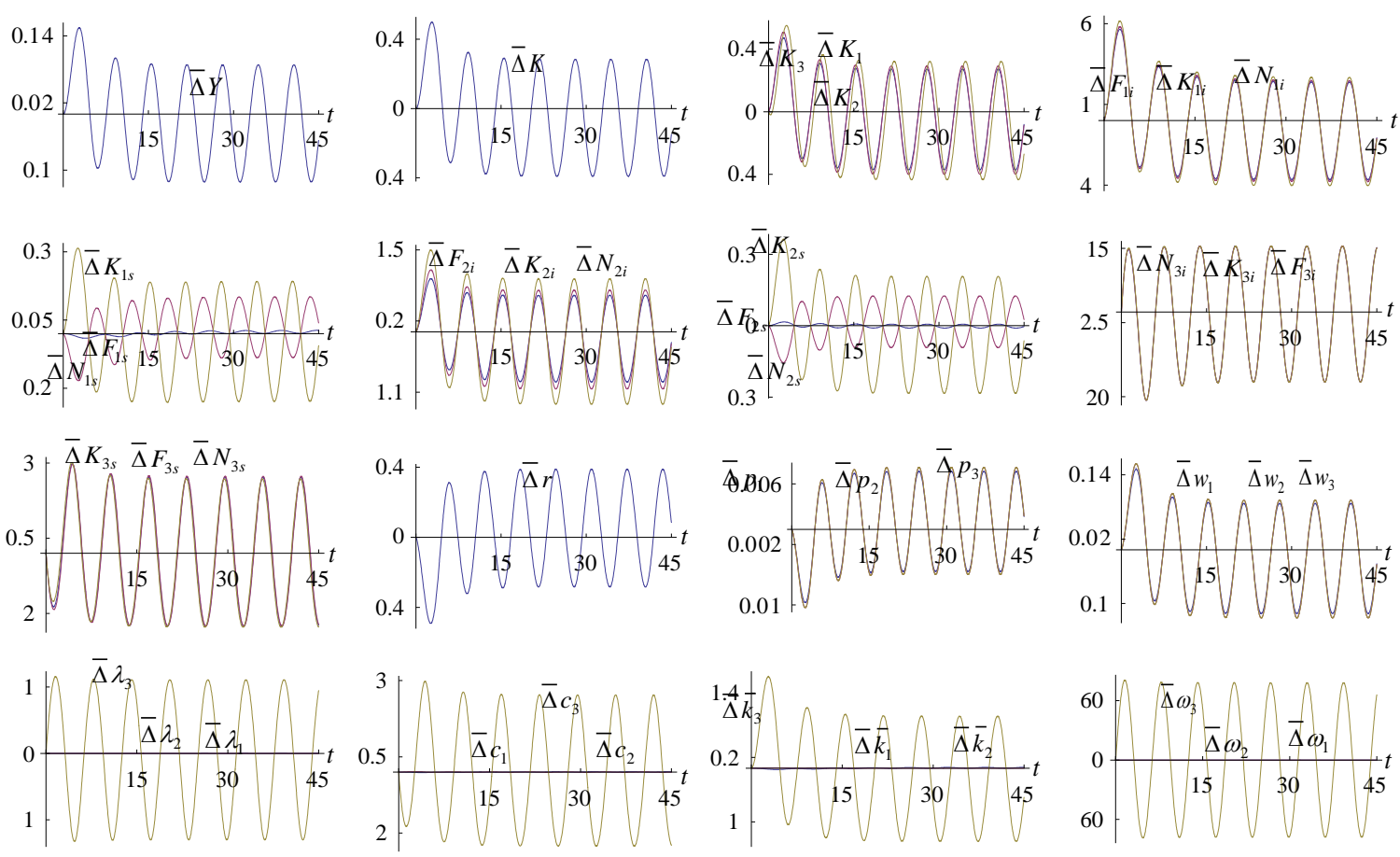

Figure 2. Perturbations in the poor country's spirit of capitalism

\subsection{Perturbations in the Poor Country's Conspicuous Consumption}

Conspicuous consumption is narrowly referred to show-off by making more consumption of consumer goods. In our modelling it is related to the weight given to social status in the function of the propensity to consume. We deal with the effects of the periodic changes in the parameter of measuring conspicuous consumption as follows

$$
\tilde{\xi}_{30}(t)=0.05+0.005 \sin (t) .
$$

The simulation result is plotted in Figure 3. The economic system experience business cycles. The macroeconomic variables of the three economies oscillate due to the exogenous periodic shocks. The output levels of the consumer good sectors in countries 1 and 2 are slightly affected, even though the input factors are change greatly. 

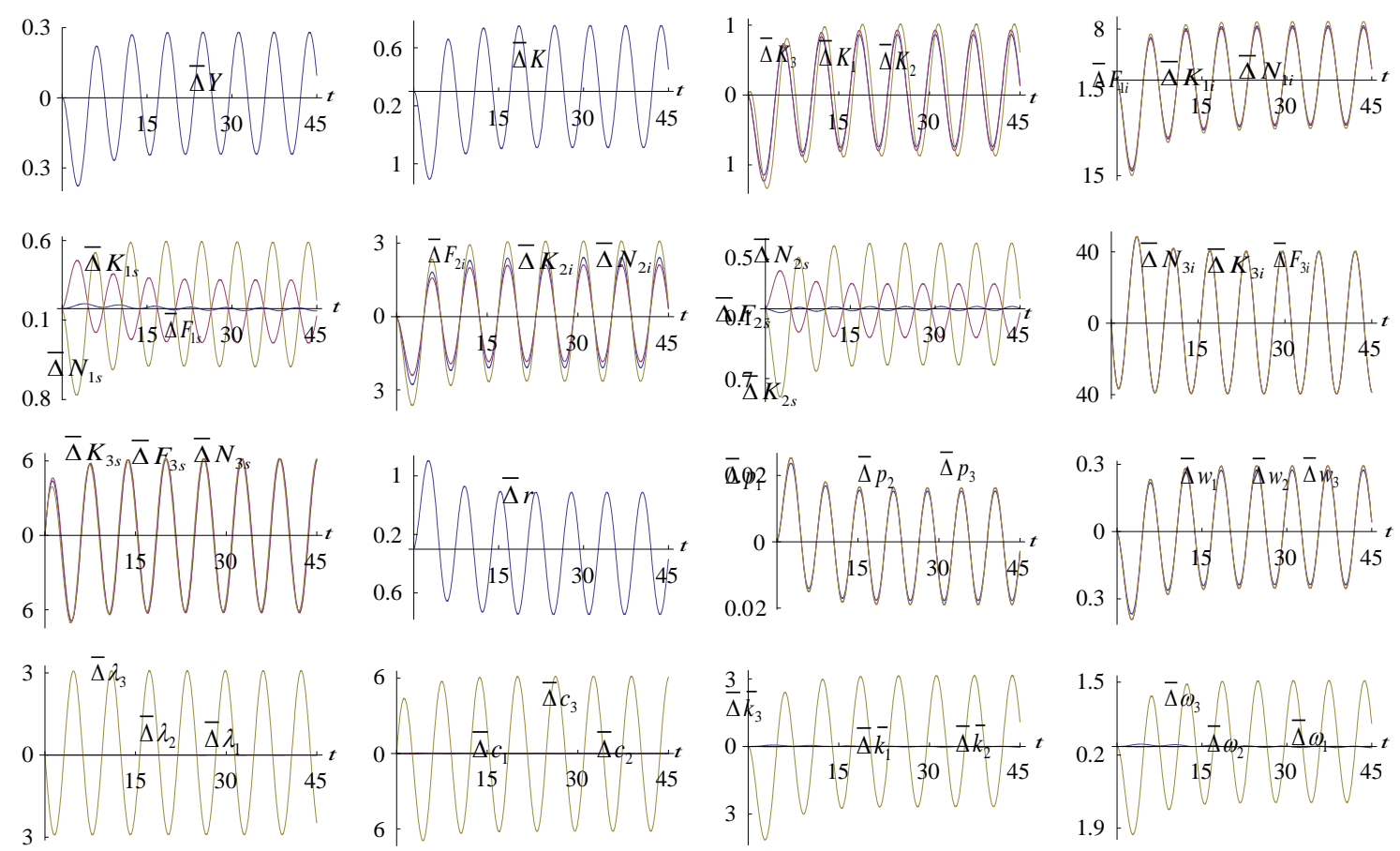

Figure 3. Perturbations in the poor country's conspicuous consumption

\subsection{Perturbations in the Rich Country's Propensity to Save}

We consider the case that the rich country's propensity to save is perturbed as follows

$$
\tilde{\lambda}_{10}(t)=0.8+0.01 \sin (t) .
$$

The simulation result is plotted in Figure 4. The economic system experience business cycles.
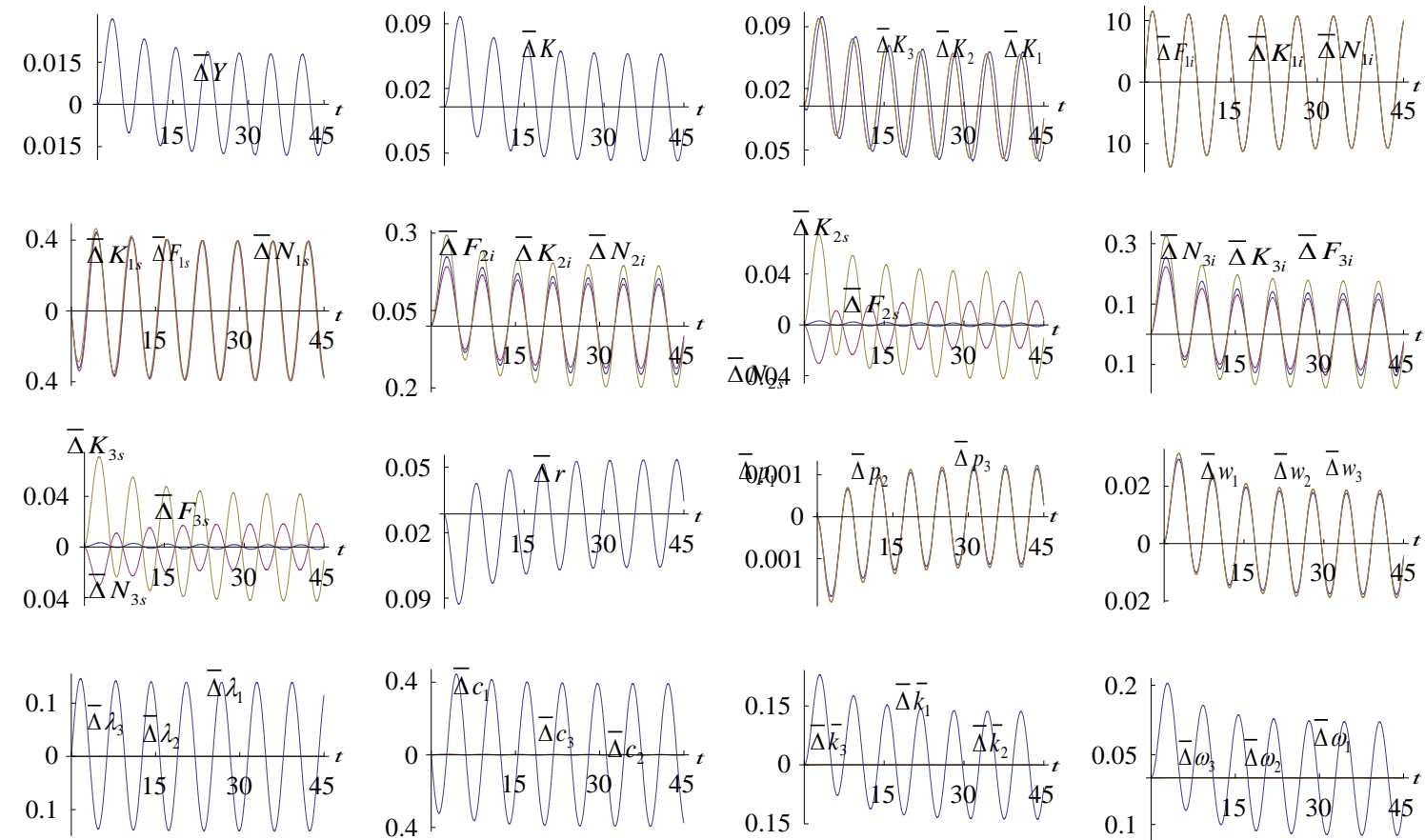

Figure 4. Perturbations in the propensity to save

\subsection{Perturbations in the Poor Country Population}

We now allow the poor country's population to be perturbed in the following way 


$$
N_{3}(t)=30+2 \sin (t)
$$

The simulation result is plotted in Figure 5.
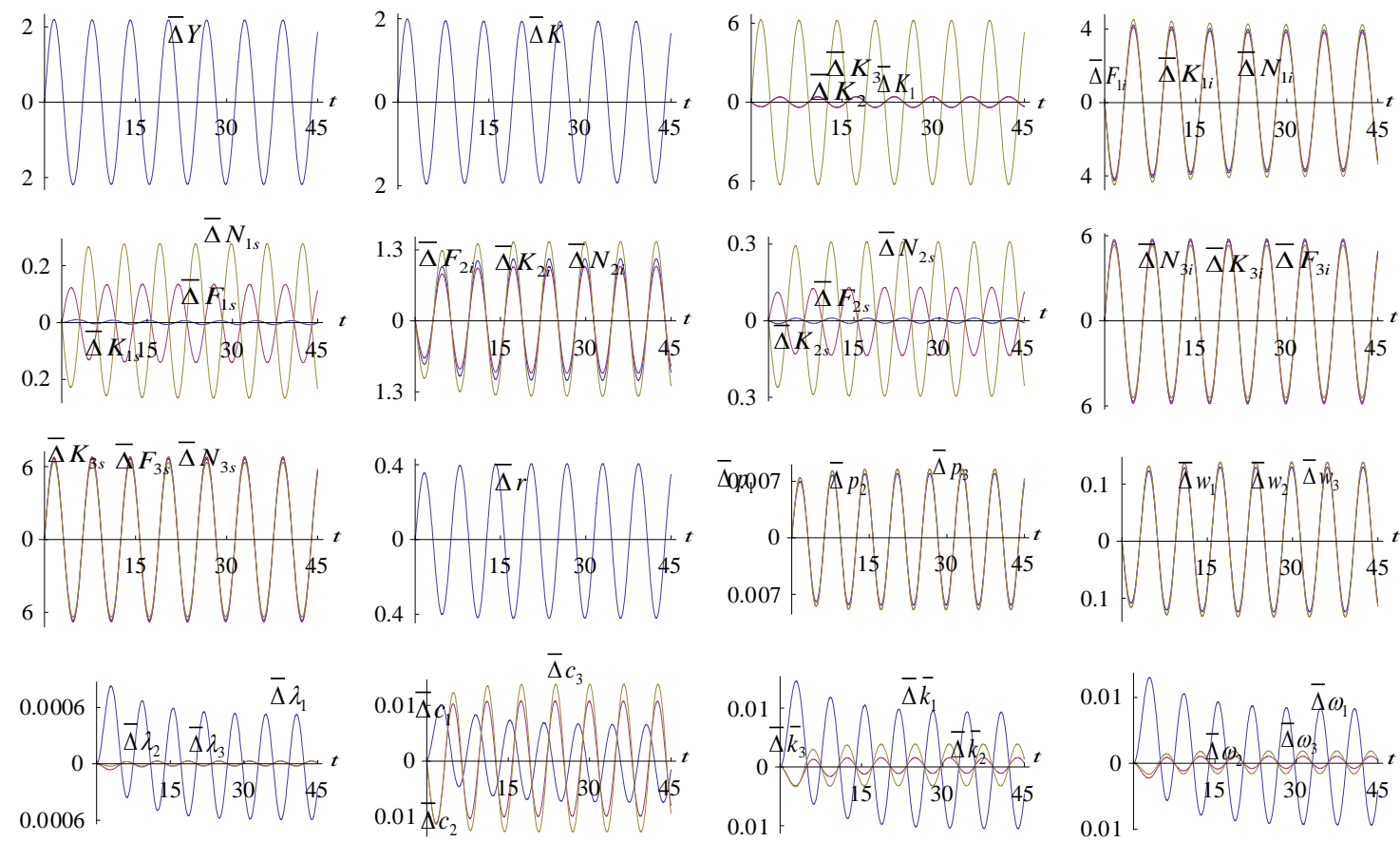

Figure 5. Perturbations in the poor country population

\subsection{Perturbations in the Depreciation Rate of Physical Capital in the Poor Country}

We now allow the depreciation rate of physical capital in the poor country to be perturbed in the following way

The simulation result is plotted in Figure 6.

$$
\delta_{3 k}(t)=0.04+0.001 \sin (t) .
$$
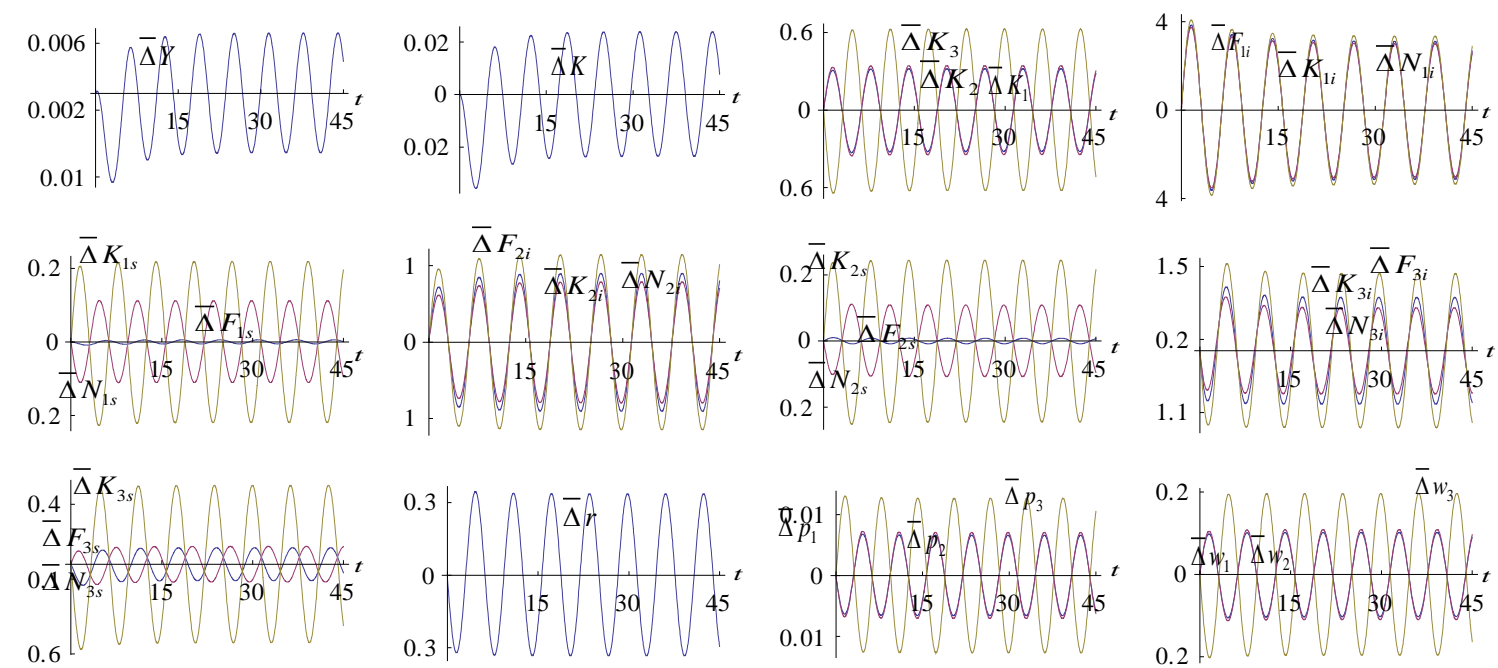

$\bar{\Delta} \lambda_{3}$
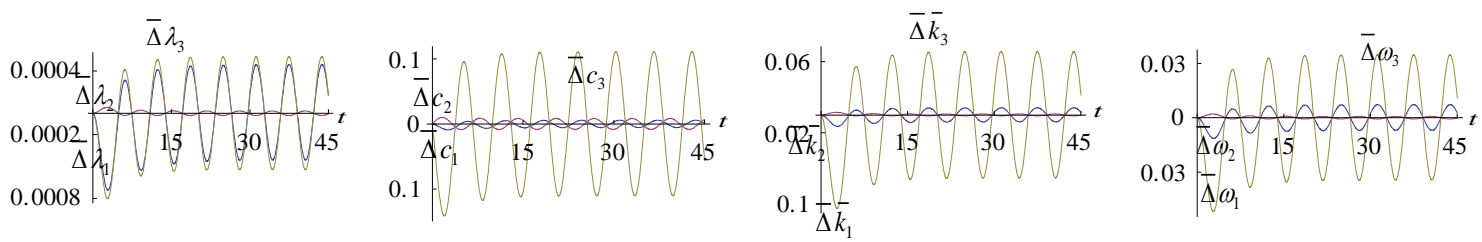

Figure 6. Perturbations in the depreciation rate of physical capital 


\subsection{Perturbations in the Rich Economy's Total Factor Productivity of the Capital Good Sector}

We examine the case that the rich country's total factor productivity of the capital good sector is perturbed as follows

$$
A_{1 i}(t)=1.7+0.02 \sin (t)
$$

The simulation result is plotted in Figure 7.
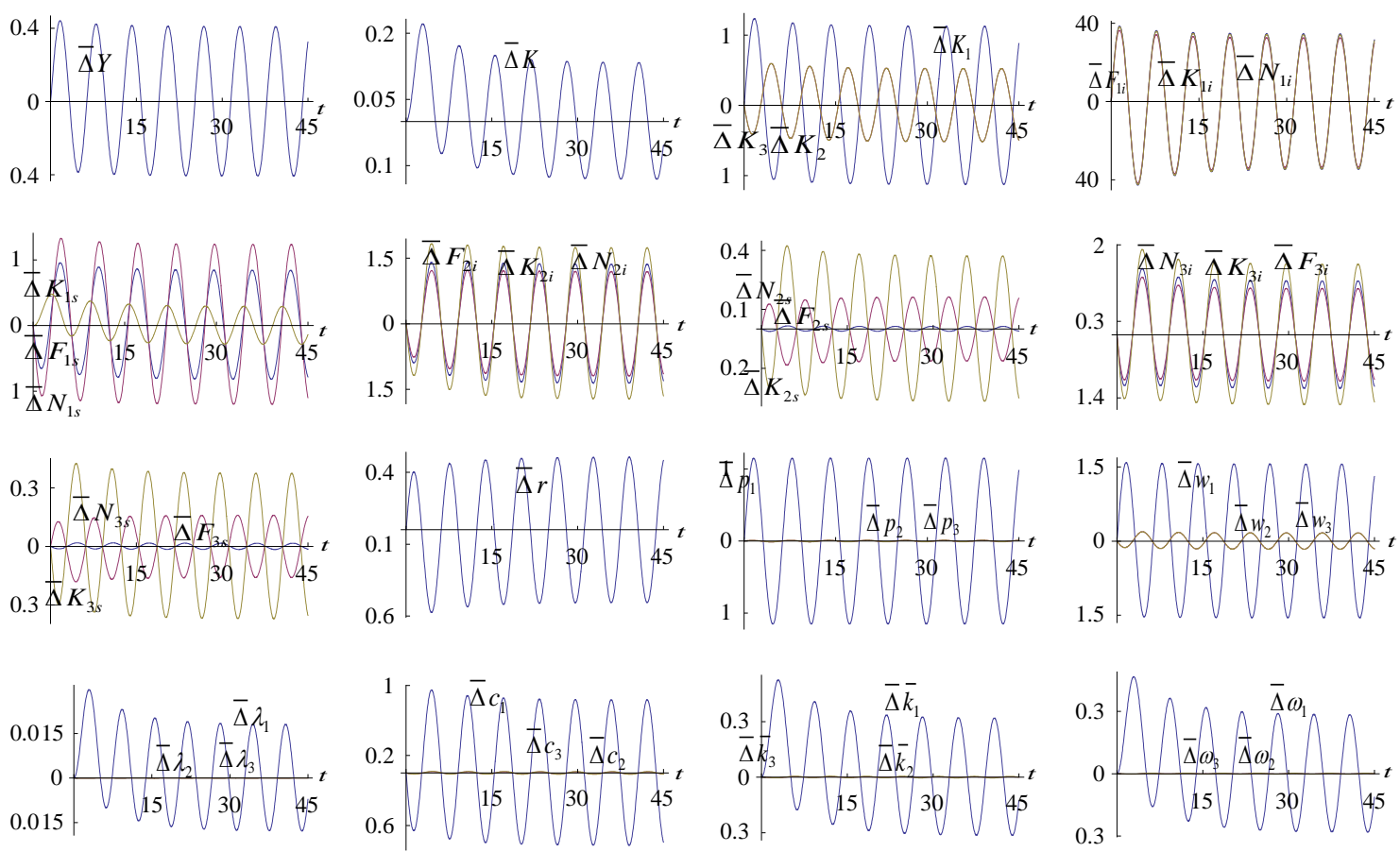

Figure 7. The total factor productivity of capital good sector rises

\section{Conclusions}

This paper generalized the global economic growth model with spirit of capitalism, social status, and conspicuous consumption recently proposed by Zhang (2016). Zhang's model examines the role of spirit of capitalism, social status, and conspicuous consumption in national and international economic development, trade patterns, and distribution of income and wealth between countries. The multi-country growth model treats social status and wealth accumulation as endogenous variables. Except the well-known growth models by Solow (1956), Uzawa (1961), and Oniki and Uzawa (1965), the model is based on by the literature on interdependence between economic growth and social status. This paper generalized Zhang's model by making all exogenous constant parameters as exogenous time-dependent parameters. We demonstrated how the system reacts to exogenous periodic perturbations. The study may be extended in different ways. For instance, we can also reveal motion of the model with some more general production functions and utility functions. It is also important to take account of different forms of taxation in the dynamic general equilibrium model.

\section{Acknowledgments}

The author is thankful for the financial support from the APU Research Subsidy, Ritsumeikan Asia Pacific University, Japan.

\section{References}

Abel, A., Bernanke, B. S., \& Croushore, D. (2007). Macroeconomics. New Jersey: Prentice Hall.

Azariadis, C. (1993). Intertemporal macroeconomics. Oxford: Blackwell.

Bagwell, L. S., \& Bernheim, D. B. (1996). Veblen effects in a theory of conspicuous consumption. American Economic Review, 86(3), 349-373.

Bakshi, G. S., \& Chen, Z. (1996). The spirit of capitalism and stock-market prices. American Economic Review, 86(1), 133-157.

Barro, R. J., \& Sala-i-Martin, X. (1995). Economic growth. New York: McGraw-Hill, Inc. 
Brecher, R. A., Chen, Z. Q., \& Choudhri, E.U. (2002). Absolute and comparative advantage, reconsidered: The pattern of international trade with optimal saving. Review of International Economics, 10(4), 645-656. https://doi.org/10.1111/1467-9396.t01-1-00355

Burmeister, E., \& Dobell, A. R. (1970). Mathematical theories of economic growth. London: Collier Macmillan Publishers.

Chang, W. Y. (2006). Relative wealth, consumption taxation, and economic growth. Journal of Economics, 88(2), 103-129. https://doi.org/10.1007/s00712-006-0185-7

Chang, W. Y., \& Tsai, F. H. (2003). Money, social status, and capital accumulation in a cash-in-advance model: a comment. Journal of Money, Credit, and Banking, 33(4), 657-661. https://doi.org/10.1353/mcb.2003.0027

Chang, W. Y., Tsai, H. F., \& Lai, C. C. (2004). Taxation, growth, and the spirit of capitalism. European Journal of Political Economy, 20(4), 1011-1125. https://doi.org/10.1016/j.ejpoleco.2003.07.001

Chen, H. J., \& Guo, J. T. (2009). Social status and the growth effect of money. Japanese Economic Review, 60(1), 133-141. https://doi.org/10.1111/j.1468-5876.2008.00460.x

Chen, H. J., \& Guo, J. T. (2011). Money, social status and endogenous growth in a generalized cash-in-advance model. Pacific Economic Review, 16(3), 267-284. https://doi.org/10.1111/j.1468-0106.2011.00547.x

Clemens, C. (2004). Status, risk-taking and intertemporal substitution in an endogenous growth model. Journal of Economics, 2(2), 103-123. https://doi.org/10.1007/s00712-004-0079-5

Cole, H. L., Mailath, G. J., \& Postlewaite, A. (1992). Social norms, savings behavior, and growth. Journal of Political Economy, 100(6), 1092-1025. https://doi.org/10.1086/261855

Corneo, G., \& Jeanne, O. (1997). On Relative Wealth Effects and the Optimality of Growth. Economics Letters 54(1), 87-92. https://doi.org/10.1016/S0165-1765(96)00940-8

Deardorff, A. V., \& Hanson, J. A. (1978). Accumulation and a long-run Heckscher-Ohlin theorem. Economic Inquiry, 16(2), 288-292. https://doi.org/10.1111/j.1465-7295.1978.tb00288.x

Duesenberry, J. (1949). Income, saving and the theory of consumer behavior. Cambridge: Harvard University Press.

Fang, H. (2001). Social culture and economic performance. American Economic Review, 91(4), 924-937. https://doi.org/10.1257/aer.91.4.924

Fershtman, C., Murphy, K. M., \& Weiss, Y. (1996). Social status, education and growth. Journal of Political Economy, 106(1), 108-132. https://doi.org/10.1086/262019

Fisher, W. H., \& Hof, F. X. (2005). Status seeking in the small open economy. Journal of Macroeconomics, 27(2), 209-232. https://doi.org/10.1016/j.jmacro.2004.01.001

Frank, R. (1985). The demand for non-observable and other non-positional goods. American Economic Review, 75(1), 101-116.

Ikeda, S., \& Ono, Y. (1992). Macroeconomic dynamics in a multi-country economy - A dynamic optimization approach. International Economic Review, 33(3), 629-644. https://doi.org/10.2307/2527130

Ireland, N. J. (1994). On limiting the market for status signals. Journal of Public Economics, 53(1), 91-110. https://doi.org/10.1016/0047-2727(94)90015-9

Ireland, N. J. (1998). Status-seeking, income taxation and efficiency. Journal of Public Economics, 70(1), 99-113. https://doi.org/10.1016/S0047-2727(98)00062-0

Konrad, K. (1992). Wealth seeking reconsidered. Journal of Economic Behavior and Organization, 18(2), 215-227. https://doi.org/10.1016/0167-2681(92)90028-A

Kurz, M. (1968). Optimal economic growth and wealth effects. International Economic Review, 9(3), 348-357. https://doi.org/10.2307/2556231

Miles, D., \& Scott, A. (2005). Macroeconomics - Understanding the wealth of nations. Chichester: John Wiley \& Sons, Ltd.

Ng, Y. K. (1987). Diamonds are a government's best friend: Burden-free taxes on goods valued for their values. American Economic Review, 77(1), 186-191.

Nishimura, K., \& Shimomura, K. (2002). Trade and indeterminacy in a dynamic general equilibrium model. Journal of Economic Theory, 105(1), 244-260. https://doi.org/10.1006/jeth.2001.2892 
Oniki, H., \& Uzawa, H. (1965). Patterns of trade and investment in a dynamic model of international trade. Review of Economic Studies, 32(1), 15-38. https://doi.org/10.2307/2296328

Ono, Y., \& Shibata, A. (2005). Fiscal spending, relative-price dynamics, and welfare in a world economy. Review of International Economics, 13(2), 216-236. https://doi.org/10.1111/j.1467-9396.2005.00500.x

Penalosa, C. G., \& Turnovsky, S. J. (2006). Growth and income inequality: Acanonical model. Economic Theory, 28(1), 25-49. https://doi.org/10.1007/s00199-005-0616-7

Rauscher, M. (1997). Conspicuous consumption, economic growth, and taxation. Journal of Economics, 66(1), 35-42. https://doi.org/10.1007/BF01231466

Rege, M. (2008). Why do people care about social status? Journal of Economic Behavior \& Organization, 66(2), 233-242. https://doi.org/10.1016/j.jebo.2006.04.005

Solow, R. (1956). A contribution to the theory of growth. Quarterly Journal of Economics, 70(1), 65-94. https://doi.org/10.2307/1884513

Uzawa, H. (1961). On a two-sector model of economic growth. Review of Economic Studies, 29(1), 47-70. https://doi.org/10.2307/2296180

Veblen, T. (1899). The theory of the leisure class. New York: Modern Library.

Zhang, W. B. (1993). Woman's labor participation and economic growth - Creativity, knowledge utilization and family preference. Economics Letters, 42(1), 105-110. https://doi.org/10.1016/0165-1765(93)90181-B

Zhang, W. B. (1994). A multi-country free trade model with capital accumulation. International Economic Journal, 8(1), 53-66. https://doi.org/10.1080/10168739400080005

Zhang, W. B. (2012). Global economic growth, trade patterns and non-tradable services. Global Business \& Economics Anthology, 1 (March), 296-306.

Zhang, W. B. (2015). How do the richest $1 \%$ own $50 \%$ of global wealth in an integrated Walrasin-general-equilibrium and Oniki-Uzawa's trade theory. Journal of Academic Research in Economics, $7(1), 7-44$.

Zhang, W. B. (2016). Spirit of capitalism and conspicuous consumption with social status in a neoclassical growth trade model. Business and Economic Research, 6(1), 70-95. https://doi.org/10.5296/ber.v6i1.8652

Zou, H. F. (1994). The spirit of capitalism and long-run growth. European Journal of Political Economy, 10(2), 279-293. https://doi.org/10.1016/0176-2680(94)90020-5

\section{Appendix: Proving the Lemma}

By (2) and (4), we get

$$
z_{j} \equiv \frac{r+\delta_{j k}}{w_{j}}=\frac{N_{j m}}{\bar{\beta}_{j m} K_{j m}}, \quad j=1, \ldots, J, m=i, s,
$$

where $\bar{\beta}_{j m} \equiv \beta_{j m} / \alpha_{j m} . \operatorname{Insert}(\mathrm{A} 1)$ in (2)

$$
r=\alpha_{j r} z_{j}^{\beta_{j i}}-\delta_{j k}, w_{j}=\alpha_{j} z_{j}^{-\alpha_{j i}},
$$

where

$$
\alpha_{j r}=\alpha_{j i} \bar{\beta}_{j i}^{\beta_{j i}} A_{j i}, \quad \alpha_{j}=\frac{\beta_{j i} A_{j i}}{\bar{\beta}_{j i}^{\alpha_{j i}}} .
$$

From (A2) we obtain

$$
r=\alpha_{j r} z_{j}^{\beta_{j i}}-\delta_{j k}=\alpha_{1 r} z_{1}^{\beta_{1 i}}-\delta_{1 k}, j=1, \ldots, J .
$$

Solve the above equations 


$$
z_{j}\left(z_{1}\right)=\left(\frac{\alpha_{1 r} z_{1}^{\beta_{1 i}}+\delta_{j k}-\delta_{1 k}}{\alpha_{j r}}\right)^{1 / \beta_{j i}}, j=2, \ldots, J .
$$

We thus determine $r, w_{j}$, and $z_{j}$, as functions of $z_{1}$. From(3) and (4), we get

$$
p_{j}\left(z_{1}\right)=\frac{\bar{\beta}_{j s}^{\alpha_{j s}} z_{j}^{\alpha_{j s}} w_{j}}{\beta_{j s} A_{j s}} .
$$

From the definitions of $\hat{y}_{j}$ and (A4), we get

$$
\hat{y}_{j}=(1+r) \bar{k}_{j}+w_{j} .
$$

Inserting $p_{j} c_{j}=\xi_{j} \hat{y}_{j}$ in (15), we have

$$
\xi_{j} N_{j} \hat{y}_{j}=p_{j} F_{j s} .
$$

Substitute (A5) into (A6)

$$
N_{j s}=g_{j} \xi_{j} \bar{k}_{j}+\xi_{j} \bar{g}_{j},
$$

where we apply $w_{j} N_{j s}=\beta_{j s} p_{j} F_{j s}$ and

$$
g_{j}\left(z_{1}\right) \equiv\left(\frac{1+r}{w_{j}}\right) \beta_{j s} N_{j}, \bar{g}_{j} \equiv \beta_{j s} N_{j} .
$$

From (11) and (A7) we have

$$
N_{j i}=N_{j}-N_{j s} .
$$

From (A1) and (16), we obtain

Inserting (A8) in (A9) we have

$$
\frac{N_{j i}}{z_{j} \bar{\beta}_{j i}}+\frac{N_{j s}}{z_{j} \bar{\beta}_{j s}}=K_{j} .
$$

$$
\bar{\beta}_{j} N_{j s}=K_{j}-\bar{f}_{j},
$$

where

$$
\bar{f}_{j} \equiv \frac{N_{j}}{z_{j} \bar{\beta}_{j i}}, \quad \bar{\beta}_{j} \equiv\left(\frac{1}{\bar{\beta}_{j s}}-\frac{1}{\bar{\beta}_{j i}}\right) \frac{1}{z_{j}} .
$$

From (A10) and (A7), we solve

$$
\bar{\beta}_{1} g_{1} \xi_{1} \bar{k}_{1}+\xi_{1} \bar{\beta}_{1} \bar{g}_{1}=K-\bar{f}_{0},
$$

where

$$
\bar{f}_{0} \equiv \sum_{j=1}^{J} \bar{f}_{j}+\sum_{j=2}^{J} \bar{\beta}_{j} N_{j s} .
$$

Inserting $K=\sum_{j=1}^{J} \bar{k}_{j} \bar{N}_{j}$ in (A11) we have

$$
\left(W \bar{k}_{1}+h_{1}\right) \xi_{1}-\bar{k}_{1}=\bar{W},
$$

where 


$$
W \equiv \frac{\bar{\beta}_{1} g_{1}}{N_{1}}, \quad h_{1} \equiv \frac{\bar{\beta}_{1} \bar{g}_{1}}{N_{1}}, \quad \bar{W}\left(z_{1},\left\{\bar{k}_{j}\right\}\right) \equiv\left(\sum_{j=2}^{J} \bar{k}_{j} N_{j}-\bar{f}_{0}\right) \frac{1}{N_{1}} .
$$

The definitions of $\xi_{j}$, (8) and (6) imply

$$
\xi_{j}=\frac{\bar{\omega}_{j 0}+\bar{k}_{j}}{\tilde{\omega}_{j 0}+\hat{\omega}_{j 0} \bar{k}_{j}}
$$

where

$$
\bar{\omega}_{j 0} \equiv \frac{\bar{\xi}_{j 0}+\tilde{\xi}_{j 0} \omega_{j 0}}{\tilde{\xi}_{j 0} \omega_{j L}}, \tilde{\omega}_{j 0} \equiv \frac{\bar{\xi}_{j 0}+\bar{\lambda}_{j 0}+\left(\tilde{\xi}_{j 0}+\tilde{\lambda}_{j 0}\right) \omega_{j 0}}{\tilde{\xi}_{j 0} \omega_{j L}}, \hat{\omega}_{j 0} \equiv \frac{\tilde{\xi}_{j 0}+\tilde{\lambda}_{j 0}}{\tilde{\xi}_{j 0}} .
$$

For the case of $j=1$ insert (A13) in(A12)

$$
\bar{k}_{1}^{2}+f \bar{k}_{1}+f_{0}=0
$$

where

$$
f\left(z_{1},\left\{\bar{k}_{j}\right\}\right) \equiv \frac{\bar{\omega}_{10} W+h_{1}-\tilde{\omega}_{10}-\hat{\omega}_{10} \bar{W}}{W-\hat{\omega}_{10}}, f_{0}\left(z_{1},\left\{\bar{k}_{j}\right\}\right) \equiv \frac{\bar{\omega}_{10} h_{1}-\bar{W} \tilde{\omega}_{10}}{W-\hat{\omega}_{10}}
$$

Solve (A14)

$$
\bar{k}_{1}=\phi\left(z_{1},\left\{\bar{k}_{j}\right\}, t\right)=-\frac{f}{2} \pm \sqrt{\frac{f^{2}}{4}-f_{0}} .
$$

There are two solutions. As shown by simulation there is a meaningful solution as follows

$$
\bar{k}_{1}=\phi\left(z_{1},\left\{\bar{k}_{j}\right\}, t\right)=-\frac{f}{2}+\sqrt{\frac{f^{2}}{4}-f_{0}} .
$$

The variables are functions of $z_{1},\left\{\bar{k}_{j}\right\}$ and $t$ given with the following procedure: $r$ and $w_{j}$ by $(\mathrm{A} 2) \rightarrow$ $z_{j}$ by (A3) $\rightarrow k_{1}$ by (A15) $\rightarrow \xi_{j}$ by (A13) $\rightarrow N_{j s}$ by (A7) $\rightarrow N_{j i}$ by (A8) $\rightarrow \hat{y}_{j}$ by (A5) $\rightarrow K_{j s}$ and $K_{j i}$ by $(\mathrm{A} 1) \rightarrow F_{j i}$ and $F_{j s}$ by the definitions $\rightarrow p_{j}$ by $(\mathrm{A} 4) \rightarrow c_{j}$ and $s_{j}$ by (13) $\rightarrow$ $K_{j}=K_{j i}+K_{j s}$. This procedure and (12) imply

$$
\begin{gathered}
k_{1}^{\&}=\Lambda_{0}\left(z,\left\{\bar{k}_{j}\right\}, t\right) \equiv \lambda_{1} \hat{y}_{1}-\bar{k}_{1}, \\
k_{j}^{\&}=\Lambda_{j}\left(z,\left\{\bar{k}_{j}\right\}, t\right) \equiv \lambda_{j} \hat{y}_{j}-\bar{k}_{j}, j=2, \ldots, J .
\end{gathered}
$$

With (A17) we take derivatives of (A15) with respect to $t$ to obtain

Equal (A18) and (A16)

$$
z_{1}^{\&}=\frac{\partial \phi}{\partial z_{1}} \&+\frac{\partial \phi}{\partial t}+\sum_{j=2}^{J} \Lambda_{j} \frac{\partial \phi}{\partial \bar{k}_{j}} \text {. }
$$

$$
\&=\Lambda_{1}\left(z_{1},\left\{\bar{k}_{j}\right\}\right) \equiv\left(\Lambda_{0}-\frac{\partial \phi}{\partial t}-\sum_{j=2}^{J} \Lambda_{j} \frac{\partial \phi}{\partial \bar{k}_{j}}\right)\left(\frac{\partial \phi}{\partial z_{1}}\right)^{-1}
$$

We confirmed the lemma.

\section{Copyrights}

Copyright for this article is retained by the author(s), with first publication rights granted to the journal.

This is an open-access article distributed under the terms and conditions of the Creative Commons Attribution license (http://creativecommons.org/licenses/by/4.0/). 